\title{
THE SELF-REPAIRING RETELLING IN THE FIGURATIVE ARTS
}

\author{
by Filomena Annigliato
}

THEORETICAL BASES AND HYPOTHESES In the book "Dream, healing and care" Giovanni Madonna exposes the systemic relational theory of the dream he conceived. In that book I wrote a chapter that stems from a careful consideration of the epistemological implications of the theory conceived by the professor Madonna and from the hypothesis of a possible application of that theory to other areas such as art. I based my hypothesis on some thesis of the dream theory: the healing processes are spontaneously generated even in the case of lacerations concerning psychic processes, these processes take the form of re-telling, that their degree of effectiveness assumes an increasing function with decreasing levels of vigilance and awareness, and that self-repairing processes are aimed at recovering internal coherence between different psychic instances that have become conflicting. Following $G$. Bateson (1967), I considered the artistic message as "a message relative to the surface of separation between conscious and unconscious" (essay "Style, grace and information in primitive art"). So we can consider art as a privileged place (together with religion, dreams, etc.), of reconnection between the distinct but not separate modes of the psychic process. I assumed that artistic production is made possible by a necessary and inevitable suspension of the conscious purpose. . I hypothesize that in this state of mind which is suspended between full awareness and lack of awareness, the possibility arises that the already active processes of self-repair may manifest themselves and that they can assume thanks to the temporary suspension of vigilant awareness a degree of effectiveness similar to that of dreams. If the processes of re-telling self-repair pertain to the attempt to reconnect between psychic instances that have become separate and conflicting, in art as in dream, this attempt can probably find expression through the juxtaposition, in a painting, of signs that "stand for" those conflicting instances and the manner in which this occurs, strident, harmonious, congruent, etc., can be an expression of the degree of effectiveness of the work in progress. These signs may appear in the same painting or sometimes even in different paintings if the gap between the various psychic instances is too wide, and if the possibility of keeping them together is too painful. I also speculate that paintings with the same subject may express, like recurrent dreams, the difficulty encountered in composing the laceration created and that in that particular subject or sign it finds its metaphorical representation. I looked for those signs that were, for me, representations of selfhealing processes, through some works by two great artists: Michelangelo Merisi known as Caravaggio and Vincent Van Gogh.

\section{CARAVAGGIO}

Looking at Caravaggio's paintings, hypothesized that in his ecology of ideas (by ideas, I mean presupposed, thoughts, affections, perceptions of the self and so on. Bateson, 1991, p. 390) there was a rift between the instances of the sacred and the profane, of pity and impiety. In many of Caravaggio's paintings it seemed to me to find traces of unconscious and not aware attempts to reconstruct the laceration created between the different instances of the sacred and the profane.

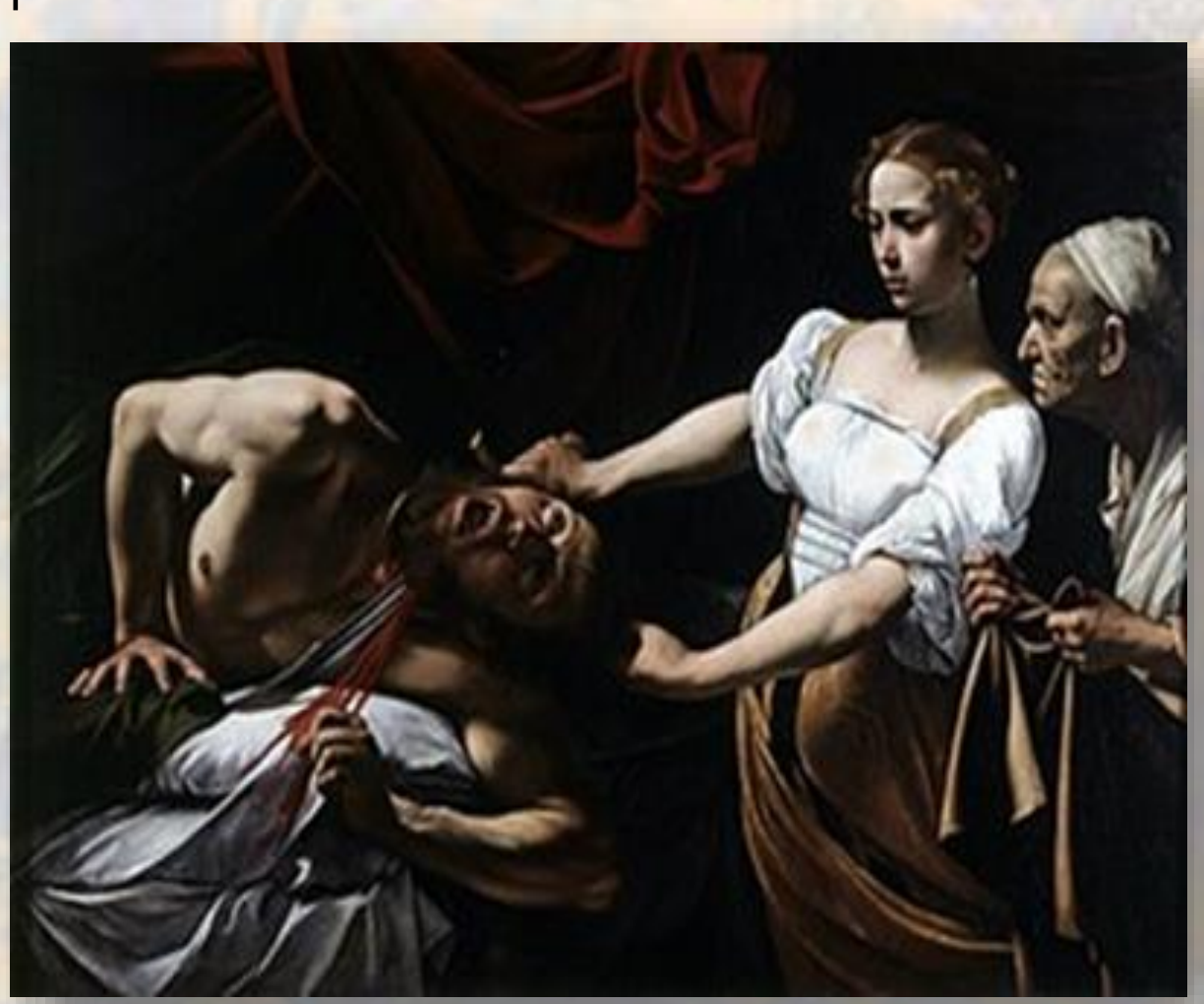

In the painting Judith and Holofernes the reconnection between the sacred and the profane does not hold up, the characteristics of one flow and are discovered equal in the other. The different instances collapse one on the ther by establishing an identity as pernicious as the fracture and separation.

There is no distinction between those who kill and those who die. The executioner becomes a victim; Judith sacrificed herself when her hands were stained with blood. In the painting Calling of St. Matthew, we can again see the sacred and the profane juxtaposed but once again the attempt to recompose the rift, fails.

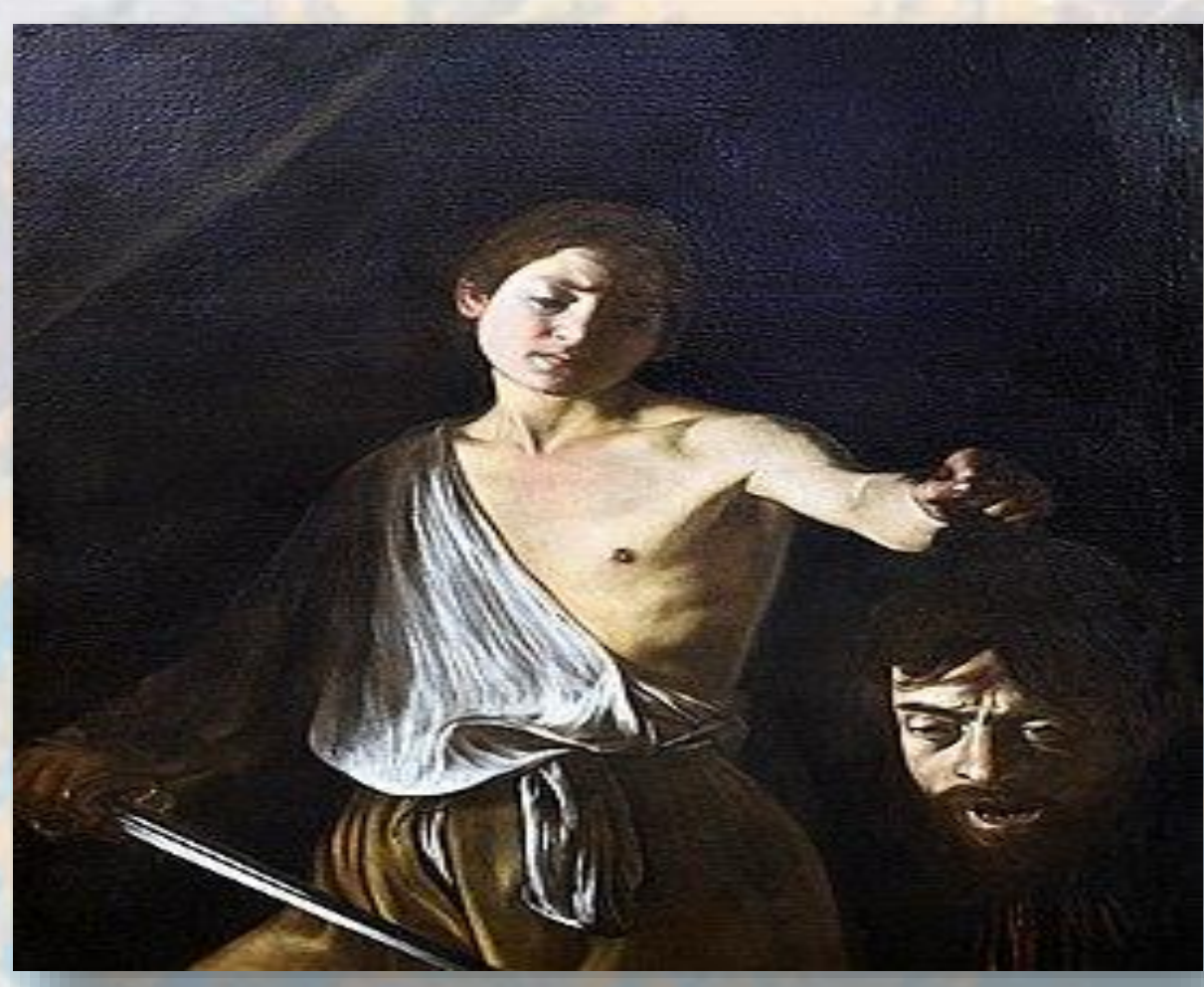

It was only with the painting David and Goliath that Caravaggio managed to recompose the various instances of the sacred and the profane. In that painting Caravaggio contemplated the possibility of his own death. That dead giant is his self-portrait. It is here that he dies and yet is saved; it is in this painting that he can show mercy for impiety. It is for this reason that Davide can have such a sad expression despite having achieved a great victory. It is only after having committed a murder that he can feel pity. It is a pity for the murderer and for the victim, it is understanding for the different and conflicting demands. It is the pity for the impiety and the impiety of that piety that reconnect the sacred and the profane.
VAN GOGH

Van Gogh became a painter after trying to become a Protestant pastor. He killed himself as man to make himself live as a painter. In art and through art Van Gogh represents life.

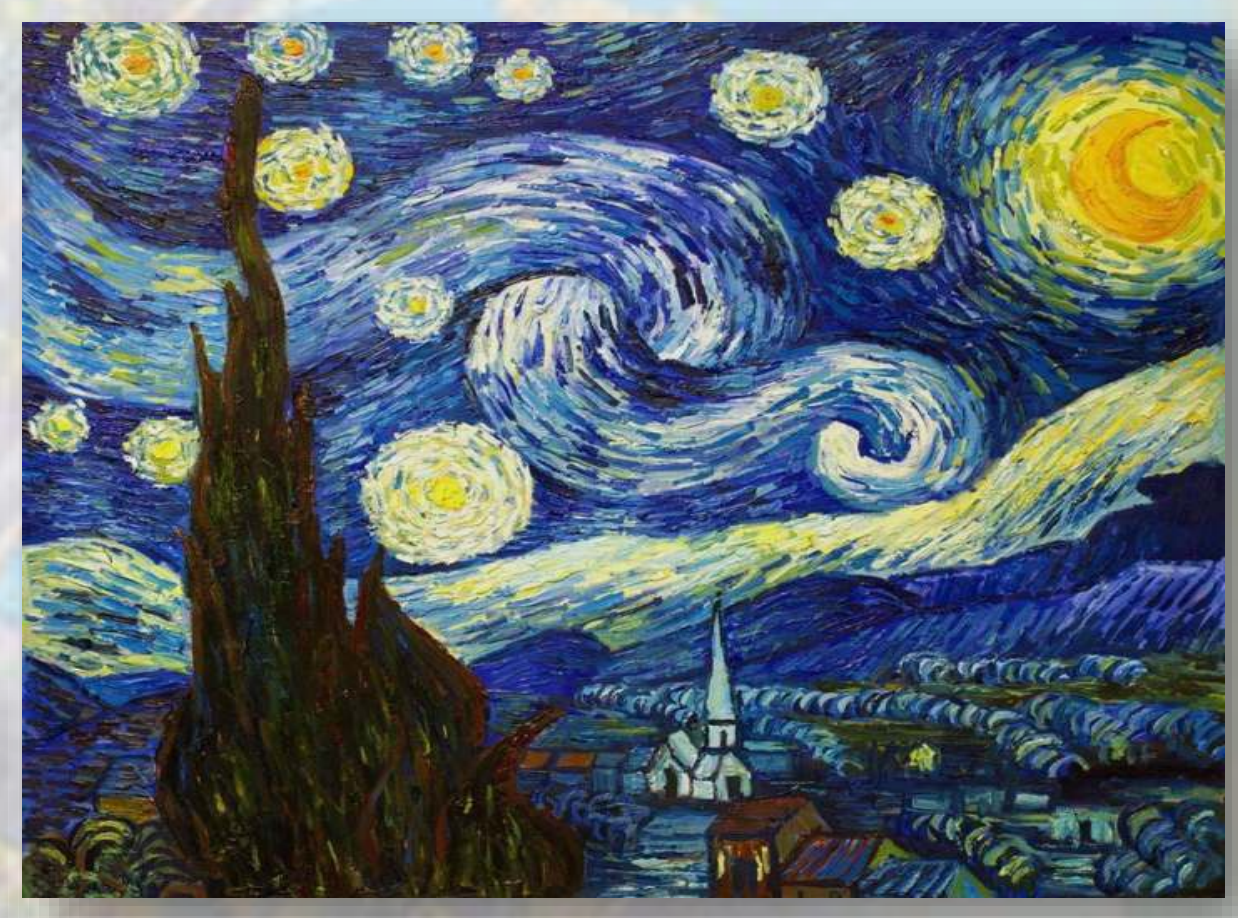

That life that seemed to speak to him through nature. In the "Starry Night" painted in June 1889, Van Gogh transforms the sky into an astral procession, where the stars and moon generate concentric vortexeses while streaks of light run across the night. Below, in the quiet, lies a village. The bell tower of the church stands out on the carpet of small houses, giving the view a counterpoint to the dark and majestic cypress that stands in the foreground. Several times in my mind I approached the differences that seemed to emerge more clearly in this painting, but each time, my search for meaning was in vain while the contours of those contrasts failed to make room for the harmony dictated by the whole. This is how I hypothesized that the many contrasts present in the "Starry Night" sent to a higher order connection where everything that is not relevant becomes pertinent in the context of a wider story. Following this hypothesis it seemed to me possible that in the ecology of Van Gogh's mind a laceration had been created between the instances of belonging and of extraneousness to the world, and that what transpires in the "Starry Night" are the signs of a work aimed at reconnecting the two separate instances. 